\title{
MEANINGFUL INTERVENTION WITH CHILDREN AND YOUTH: A REFLECTION ON TEN YEARS OF INQUIRY
}

\author{
Sibylle Artz, Diana Nicholson, Elaine Halsall, and Susan Larke
}

\begin{abstract}
It has been known since the early 1970s that youth risk assessment does not necessarily assist us in determining youth needs and services. Still, where young people and crime are concerned, interventions are often focused on risk assessment rather than need assessment, especially when these young people face incarceration. In this article we emphasize needs assessment and the development of a youth friendly approach to such assessment. We draw on a number of community-based and community involved studies that were conducted over a tenyear period, studies that focused on the perspectives, experiences, and needs of children and youth, and present as key among these studies a project on the development of a gender-sensitive tool for needs assessment that can aid workers with youth engagement and needs focused intervention.
\end{abstract}

The analysis presented here is drawn from a number of studies conducted over a ten-year period. These research and development projects focused on the perspectives, experiences, and needs of children and youth. Key among these studies is a project on the development of a gender-sensitive tool for needs assessment ${ }^{1}$, but also included are inquiries that focused explicitly on the experiences of children and youth from Kindergarten to Grade 12 with school and community-based violence ${ }^{2}$, gender differences in perceptions of and experience with aggression and violence ${ }^{3}$, and their experiences of being incarcerated ${ }^{4}$. Included in each of these studies were the perceptions, experiences, and practices of workers and, in some cases, parents (Nicholson, Artz, Armitage, \& Fagan, 2000). All these studies involved partnerships with community-based agencies or institutions.

\footnotetext{
${ }^{1}$ (Artz, Nicholson, Halsall, \& Larke, 2002). This study was funded by the National Crime Prevention Centre, Department of Justice Canada.

2 (Artz, Riecken, Van Domselaar, \& Laliberté, 1994; Artz, 1998; Artz, Riecken, MacIntyre, Lam, \& Maczewski, 1997, 1998, 1999, 2000). These studies were funded by the British Columbia Health Research Foundation, the Vancouver Foundation, and The British Columbia Ministry of Education Research Branch.

${ }^{3}$ (Artz, Riecken, et al., 1997, 1998, 1999, 2000; Artz, 1998; Artz, Blais, \& Nicholson, 2000a, 2000b). These studies were also funded by the National Crime Prevention Centre, Department of Justice Canada.

${ }^{4}$ (Artz, Blais, \& Nicholson, 2000a).
} 


\section{Current Thinking}

Our most recent work on the development of a gender-sensitive guide for needs assessment (Artz, Nicholson, Halsall, \& Larke, 2002), which encompassed a literature search of over 1,500 journal articles, books, and studies that spoke to needs assessment in children and youth, suggested that understanding these needs is never a "once and for all” undertaking. Child and Youth Care and other human service workers must assess and respond to the needs of those they work with on an almost constant basis. We found that the process of needs assessment and of matching need to service is difficult for a number of reasons, including the lack of a consistent and universal definition of what constitutes a need (Colton, Drury, \& Williams, 1995). Further, in human services, needs are often confused with risks. As Anglin (1999) points out, when child welfare legislation shifted to require the assessment of and response to the possibility of future harm, the child welfare system responded by introducing procedures to assess and reduce risk. Hence, the term often used to describe children and youth requiring some form of social services is "at risk".

This emphasis on risk was noticeable during conversations with child and family services workers at the commencement of our needs assessment project. We found that most workers turn quickly to thinking about risk and reducing risk and increasing resiliency when they discuss assessing the needs of youth. Our review of the literature on needs assessment also pointed to the prevalence of a focus on risk and resiliency even when document titles implied a needs focus (Henderson, Aydlett, \& Bailey, 1994; Hodges, 1999; Kroll et al., 1999; Ottenbacher, Taylor, Msall, \& Braun, 1996; Towberman, 1992). However, as early as the 1970s, researchers were starting to discuss the fact that assessing for risk does not assist workers in finding the information that they require in order to determine who needs services and what kinds of services might be of the most benefit.

Garmazy (1971) approached risk assessment with caution and introduced the notion of "flipping the coin of risk statistics" (p. 112), based on his observation that most individuals deemed at risk do not develop psychopathology. Garmazy made clear that the presence of a risk factor or an adversarial circumstance in the life of an individual is not predictive of what will happen in the future. This observation has been confirmed by Werner and Smith (1992) and others. For example, Masten (1999) found that more than half of the children studied, who were categorized as high risk, grew up to be happy, successful people. This suggests that a focus on risk factors alone will not help researchers or workers to predict or determine outcome (Mangham, McGrath, Reid, \& Stewart, 1995), nor will it help to determine need.

Our search of the literature on needs assessment revealed that in the past few years there appears to be a trend toward focusing increasingly on the use of standardized assessment instruments in work with children and youth (cf., Sattler \& Hoge, 2006). This trend concerns us because standardized tools generally focus on the individual without consideration of the context in which they live and how contextual factors influence their needs and capabilities. 
A welcome departure from standardized assessment is found in Berberet's (2006) integrated assessment approach to program planning. Berberet (2006) stresses the importance of including youth's perspectives on their situations and needs and contrasting these with assumptions made by adults engaged in serving the youth. Berberet also points out that many youth workers acknowledge the fact that they don't understand the needs of the populations they serve. We have heard the same acknowledgement from workers in our research and it was their desire to better understand the populations they serve that provided the impetus for development of our needs assessment guide for youth (Artz, Nicholson, Halsall, \& Larke, 2002). Thus, along with Berberet (2006), we take seriously the challenge of determining need and now turn to some promising current responses to children and youth that we wish to highlight.

\section{Current Responses to Children and Youth and Their Effects}

Four key documents are considered here in relation to current responses to children and youth and the effects of such responses:

1. The Policy Framework from the British Columbia Ministry for Children and Families (2000);

2. The Policy Recommendations from Civicus 2001 (Sharpe, 2001a, 2001b);

3. The Circle of Courage (Brendtro, Brokenleg, \& Van Bockern, 1990) found also in a Developmental Audit of Delinquency prepared for the W. K. Kellogg Foundation by Augustina College and the Reclaiming Youth Institute (Van Bockern \& Brendtro, 1999); and

4. The Emergent Practice Planning Model (Ricks \& Charlesworth, 2000), an approach to service that takes into account the "emergent", that is, always fluid nature of intervention.

\section{The Youth Policy Framework}

The Youth Policy Framework (British Columbia Ministry for Children and Families, 2000) outlines needs of youth that are similar to those articulated in the national youth policy documents presented at the Civicus Conference in 2001 (Sharpe, 2001a, 2001b). The Youth Policy Framework proposes to address youth's needs within the context of key environmental influences that affect the youth's health and well-being. The influences highlighted are the social and economic conditions in which youth live, play, and work, their sense of control, and their family and social connections. The needs attached to these areas of influence are itemized in Table 1 below: 
Table 1: British Columbia Youth Policy Framework

\begin{tabular}{|c|c|}
\hline Key Influences: & Needs: \\
\hline $\begin{array}{l}\text { Social and economic conditions, in which youth } \\
\text { live, play, and work. }\end{array}$ & $\begin{array}{ll}\text { - } & \text { Basic needs met (housing, food, clothing) } \\
\text { - } & \text { Safety and security } \\
\text { - } & \text { Opportunities for learning, work, and play }\end{array}$ \\
\hline Family and social connections & $\begin{array}{ll}\text { - } & \text { Family and cultural connections } \\
\text { - } & \text { Peer relationships } \\
\text { - } & \text { Adult relationships } \\
\text { - } & \text { Mentors } \\
\text { - } & \text { Schools } \\
\text { - } & \text { Community } \\
\end{array}$ \\
\hline Sense of control over their lives & $\begin{array}{ll}\text { - } & \text { Value and respect } \\
\text { - } & \text { Information, knowledge, and decision-making } \\
& \text { skills } \\
\text { - } & \text { Meaningful participation } \\
\text { - } & \text { Opportunities for self-definition } \\
\text { - } & \text { Creating positive futures } \\
\end{array}$ \\
\hline
\end{tabular}

\section{The Policy Recommendations from Civicus 2001}

The Policy Recommendations from Civicus 2001 (Sharpe, 2001a, 2001b) provided directions for integrating national youth policies into a long-term strategic global perspective for youth. In the primary document, The Education of Young People (Sharpe, 2001a), and the working paper, National Youth Policies: Towards an Autonomous, Supportive, Responsible and Committed Youth (Sharpe, 2001b), similar sentiments are expressed regarding the importance of understanding cultural diversity. Sharpe (2001b) states that while "the specific needs of young people will vary from one culture to another, and, indeed from one individual to another depending on circumstances” (p. 8), youth around the world share similar needs for growth and development. Sharpe concludes that young people from all environments share the same basic needs to become autonomous, supportive, responsible, and committed adults. The four outcomes associated with these needs are given in Table 2 below:

Table 2: Four Essential Needs in Youth (Sharpe, 2001a, 2001b).

\begin{tabular}{|l|l|}
\hline Needs & Outcomes \\
\hline Autonomous & $\begin{array}{l}\text { Able to make choices and control their personal and } \\
\text { social life as an individual and as a member of society. }\end{array}$ \\
\hline Supportive & $\begin{array}{l}\text { Able to show concern for others, to act with them and } \\
\text { for them, to share concerns. }\end{array}$ \\
\hline Responsible & $\begin{array}{l}\text { Able to take responsibility for their actions, keep } \\
\text { commitments, and complete whatever they undertake. }\end{array}$ \\
\hline Committed & $\begin{array}{l}\text { Able to assert themselves in respect to values, a cause, } \\
\text { or an ideal to act accordingly. }\end{array}$ \\
\hline
\end{tabular}




\section{The Circle of Courage}

In 1990, Brendtro, Brokenleg and Van Bockern established the Circle Of Courage, a model for understanding the core needs of all young people based on a combination of Native American child-rearing practices, psychology, and the research and practices of North American youth-work pioneers. This model is based on the interconnection of four areas or quadrants of influence and experience that are central to all children's lives, where each quadrant represents "the four overriding needs of young people: Belonging, Mastery, Independence, and Generosity” (p. 173). Brendtro and his colleagues contend that if any of these needs remain unmet, "the child is at risk and is in danger of being hurt, [and a] hurting child hurts others" (p. 173). Thus, need exists before risk surfaces and, therefore, should not be considered solely as a function of risk.

Van Bockern (1998) subsequently examined the needs of youth against the Circle of Courage by following the paths of two males from youthful delinquency to adult criminality. He found that these young people suffered from a lack of parental support, negative school experiences, and had moved from committing minor offences (shoplifting) to incarceration for murder and assault. Van Bockern notes that "the bonds that transmit basic human needs from adults to the young began unraveling for Howard and Bobby during their earliest years” and suggests that as a result these children were seeking to fill their needs for belonging, mastery, independence, and generosity with "gangs and connections to false friends and relationships with adults who will exploit youth" (p. 173). According to Van Bockern, youth will seek mastery through "snatching purses, stealing chickens, or displaying sexual prowess on the video screen” (p. 173). Independence will be represented as "a sense of control sought in drugs and alcohol; generosity is measured by the amount of drugs and alcohol shared with others" (p. 173). While the means to meet these needs by youth may be misguided, Van Bockern asserts that youth are pursuing "worthy ends... they haven't given up; they are struggling to fix discouraging life situations” (p. 174).

Van Bockern (1998) thus suggests that, rather than focusing upon the deviance and pathology of troubled children, youth would be better served if their behaviours were seen as attempts to cope with very abnormal life situations and circumstances. Such an approach would not involve adults "reciprocating with counter-aggression" when the youth responds with rage and rebellion (p. 173). Instead, workers would use responses that "disengage and de-escalate conflict" and involve "listening and responding with empathy, while also clarifying for children their needs and feelings and helping them take responsible actions through coping skills” (p. 174).

Van Bockern's (1998) notions are echoed by literature that focuses on the importance of workers' avoidance of becoming caught up in children and youth's challenging behaviours and suggests that they should instead consider these behaviours as indicative of underlying need (Richardson, 2001). Maier (1991) stresses the importance of seeing youth's challenging behaviours as unusual rather than as deviant and of viewing challenging behaviours in terms of how they fit into a child or youth's developmental progression. Thus, care workers need an understanding of child 
development, which allows them to understand a youth's pattern of coping with specific life situations and therefore helps them to determine what the young person's next developmental task should be. According to Maier, such a developmental focus holds more promise than working towards undoing or correcting unwanted behaviours.

\section{Emergent Practice Planning}

Ricks and Charlesworth (2000), in their manual on Emergent Practice Planning, note that practitioners' approaches to need are premised on their preferences for various behaviour change theories and framed by their favourite interventions rather than by their clients' perspectives and assessment of the situation. Ricks and Charlesworth suggest that, rather than framing a client's needs through their own eyes, practitioners should frame their interventions with the client, to see to it that these interventions are related to the client's need(s) and are possible and realistic given the client's present level of functioning and capacity. According to Ricks and Charlesworth, assessment should focus on working with clients to establish needs and goals so that the formulation of service action plans can promote change in ways that are meaningful to clients.

\section{Promising Practices and Approaches for Effectively Meeting the Needs of Children, Youth, and the Community}

\section{Positive Relationship Development}

Consultation with youth and workers from three Vancouver Island communities (Artz, Nicholson, Halsall, \& Larke, 2002) underlined the point that positive relationships are essential to needs assessment and to meaningful intervention. The importance of relationship was also noted by Clarke (2001) who, in his research on 40 years of psychotherapy outcome studies, found that after individual client factors, such as capability, capacity, and potential which account for $40 \%$ of behaviour change, positive worker-youth relationship accounts for 30\% of behaviour change. Along with client factors and relationship, the worker's ability to instill a sense of self-efficacy and possibility, i.e., hope and positive expectations in the youth, account for $15 \%$ of behaviour change. Finally, intervention techniques, programs, or models account for the remaining $15 \%$. Thus, taken together, client capability, the relationship between client and worker, and hope and expectancy account for $85 \%$ of behaviour change, while technique accounts for only $15 \%$.

The importance of relationships was also noted in research on school-based violence prevention. Students involved in violence prevention appeared to respond more favourably to violence prevention programming if they were systematically positively reinforced by adults for pro-social behaviour, if their teachers and parents were involved with them in a variety of activities, not just violence prevention programs, and if their parents and teachers used respectful communication and conflict resolution skills with them. Also important to these students were opportunities to participate in teaching others bully prevention techniques and, especially for girls, to be involved in groupbased social skills training (Artz, Riecken, MacIntyre, Lam, \& Maczewski, 2000). 
Positive relationships were also emphasized by youth in custody and girls interviewed in the context of research on their use of violence. These young people expressed great faith in counsellors and teachers who listened to them, took the time and trouble to give them information relevant to their problems, and spent time talking and joking with them. Workers and teachers who used put-downs, coercion, and intimidation were described by these young people as contributing to their negative behaviour, as were those who labelled them by using pejorative terms such as "uncontrollable" or “deviant” (Artz, 1998; Artz, Blais, \& Nicholson, 2000a).

Youth told us repeatedly that they do not cooperate with workers with whom they have no established connections or with assessments that they believe are disrespectful and intrusive - that is, assessments that ask them to answer what youth described as “irrelevant and demeaning” questions about their personal lives, relationships, and activities. Clarke (2001) also recognized this dynamic and stressed a very important point often overlooked by adults: It is the youth's assessment of her or his relationship with the worker that matters. If a young person doesn't feel positive about and involved in the relationship with the worker, the relationship doesn't really exist, regardless of how it may be defined by the worker.

Clarke (2001) also comments on the reason why diagnoses of problems based on impersonal assessments don't work: Children and youth are active and generative; the severity, magnitude, and frequency of problems are constantly changing, and change itself is a powerful client factor. Thus, as he points out, we do young people a profound disservice if we take an approach that represents their problems as static and constant, that is, captured in diagnostic labels, because this implies that their presenting complaints have a quality of permanence that is contradictory to the notion of change. Clarke states that worker "expertise continues to be vital and required; but only to guide and raise the three critical ingredients - the tactical triad - of a youth's resources, perceptions and participation” (p. 26). These critical ingredients should, therefore, be a part of any assessment. Workers should not focus on "what is wrong and what a child or youth cannot do," but instead on what young people can already do, on their resources, on what they think and feel, and on what they are willing to try.

\section{The Importance of Gender and Culture}

Gender and culture have long been neglected aspects of research and practice and this neglect perpetuates systemic discrimination (Hannah-Moffat \& Maurutto, 2003). Our research and that of numerous others showed that gender and culture are important considerations that must be included in any intervention because our individual experiences in each of these areas shapes how we see others and ourselves (Artz, 1998; Artz, 1999; Artz, Riecken, et al., 1997, 1998, 1999, 2000; Artz, Nicholson, \& Blais, 2000a, 2000b; cf., Canada, 1998; Garbarino, 1999; Gilligan, 1982; Kemp, Whittaker, \& Tracy, 1997; Leadbeater, Blatt, \& Quinlan, 1995; Lezak, 1995; Miller, 1976; Pipher, 1994; Plummer, 1999; Pollack, 1998; Riecken, 2000; Tanenbaum, 1999; Taylor, 
Gilligan, \& Sullivan, 1995). So, too, must sexual orientation (Daley, 1998; DuBeau, 1998).

Artz, Riecken, et al. (1997, 1998, 1999, 2000) found that gender plays a major role in students' perceptions of and experiences with violence, as well as in how students respond to violence prevention. Gender also plays a role, both in how students and their parents participate in violence prevention, and in how teachers involve themselves in violence prevention, particularly pertaining to intervention. This series of studies conducted by Artz and her colleagues showed that females (students, teachers, and parents) were more concerned about violence and participated more in violence prevention efforts; that female students were more receptive to violence prevention programming and changed their attitudes and behaviours toward non-violence to a significantly greater degree than their male counterparts; that male students were more often both victims and perpetrators of violence but less willing to desist from endorsing and using violence; and that male teachers were less intimidated with regard to acting to end a violent altercation between students. Reicken (2000) suggests that these gender differences have their origins in a cultural milieu that exposes males to more violence than is the case for females, while also expecting - even demanding - from boys and men a greater readiness to accept and deal with violence.

The importance of considering gender and culture was further examined in Artz, Blais, and Nicholson (2000a, 2000b) where it was found that gender and culture play a significant role in how custody workers and probation officers relate to their clients and to each other, and in how youth in custody and on probation relate to each other and to workers. We also previously found that gender and culture play a central role in how assessment is conducted and how and what resources are made available (Artz, Nicholson, Halsall, \& Larke, 2002).

We believe that, within any given society, there are different expectations and demands for behaviour, beliefs, and adaptations across different situations and subcultures. These differences result in wide cultural and gender-based variation in concepts of self, styles of communication, coping mechanisms, and what is considered adaptive or appropriate (Neisser et al., 1996). The need for culture- and gender-based influences to be carefully considered and explored as part of any intervention or service action is, therefore, paramount because unexamined culture- or gender-based assumptions may result in confusion, misinterpretation, and misattribution of labels and causes (Lezak, 1995). Before conclusions are drawn about clients' lives, any culture- or gender-based explanations of issues or problems should be explored, examined, and understood (Sattler, 1992).

Each youth has needs that are unique to that individual. A relationship-focused process of assessment enables youth workers to draw out the necessary information to build a continually evolving understanding of where each youth is individually, developmentally, and culturally. We acknowledge that some youth may have pressing needs associated with mental health or developmental challenges. Our approach to assessment can be described as inclusionary and differential. By including youth in 
discussions about their own situations and needs, workers can build an understanding of the influences of culture, gender, and development.

Our approach to assessment also allows the differential needs of boys and girls from diverse cultural backgrounds and experiences to be considered in matching the needs of youth to effective interventions (Reitsma-Street, Artz, \& Nicholson, 2005). For example, responsive practice based on the differential and inclusionary assessment approach we promote can involve taking diverse learning styles, cognitive abilities, and emotional maturity of youth into account when planning appropriate interventions (Reitsma-Street, 2004). Nuanced differences in a youth's ability to tolerate ambiguity, uncertainty, and authority can all be taken into account when needs assessment permits insights into the differential effects of gender, culture, and development. In this way, our approach can be readily adapted to work with youth that experience mental health and developmental challenges.

In our view, recognition of the complex interplay between individuals and their social and physical worlds in the creation of need is the most appropriate starting point for assessing and responding to needs. Young people's needs are dependent upon context and resource. Meeting these needs invariably involve working with contexts and even changing contexts rather than merely changing individual behaviours. We therefore suggest an approach to needs assessment that is ecological and inclusionary and highlights an individual's strengths and ability to negotiate contexts rather than focusing only on personal risks and deficits.

\section{Ways of Establishing or Enhancing Partnerships}

\section{Caring and Collaboration}

With children and youth, partnerships are initially established and enhanced through a clear and unambiguous message of caring. Youth research participants stated repeatedly that only those workers who they believed genuinely cared about them received their trust, and along with their trust, their cooperation (Artz, Blais, \& Nicholson, 2000a; Artz, Nicholson, Halsall, \& Larke, 2002).

Among agency workers, whether that is within or across agencies, the following detractors and facilitators were found to be influential on workers' ability and willingness to work collaboratively (Nicholson et al., 2000, p. 56). 
Table 3: Organizational Detractors and Facilitators of Collaborative Practice (Nicholson, Artz, Armitage, \& Fagan, 2000)

\begin{tabular}{|c|c|c|}
\hline & Detractors & Facilitators \\
\hline $\begin{array}{l}\text { Organizational } \\
\text { Factors }\end{array}$ & $\begin{array}{ll}\text { - } & \text { high caseloads } \\
\text { - } & \text { low resources } \\
\text { climate of uncertainty around } \\
\text { - } & \text { reorganization } \\
\text { lack of administrative support } \\
\text { to coordinate/plan meetings } \\
\text { and schedules } \\
\text { - } \\
\text { hiring staff without experience } \\
\text { with collaborative approaches } \\
\text { lack of a formal communication } \\
\text { structure }\end{array}$ & 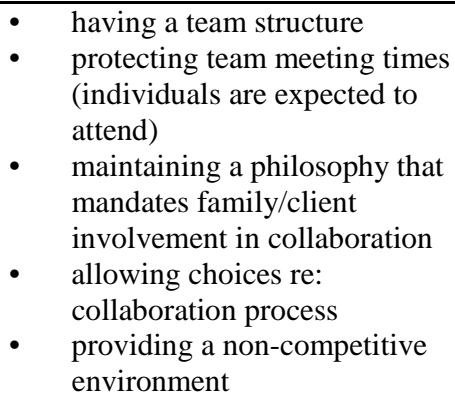 \\
\hline
\end{tabular}

Table 4: Individual Detractors and Facilitators of Collaborative Practice (Nicholson, Artz, Armitage, \& Fagan, 2000)

\begin{tabular}{|c|c|c|}
\hline & Detractors & Facilitators \\
\hline Individual Factors & $\begin{array}{ll}\text { - } & \text { not sharing work } \\
& \text { not being able to express limits } \\
\text { - } & \text { around work and own abilities } \\
\text { - } & \text { needing to control others } \\
\text { - } & \text { needing to work autonomously } \\
& \text { accepted }\end{array}$ & $\begin{array}{ll}\text { - } & \text { flexibility } \\
\text { - } & \text { self-awareness } \\
\text { - } & \text { commitment to collaboration } \\
\text { - } & \text { accepting of individual differences } \\
\text { - } & \text { good communication } \\
\text { - } & \text { developing and valuing personal } \\
\text { - } & \text { relationships with co-workers } \\
& \text { understanding others, their } \\
\text { - } & \text { roles, and contributions } \\
& \text { educating others about self, } \\
& \text { own role, and contributions }\end{array}$ \\
\hline
\end{tabular}

The promising practices outlined above and the detractors and facilitators noted by Nicholson et al. (2000) were also identified by teachers, parents, and family counsellors of children under the age of 12 years with severe behaviour problems, who participated in a study with the objective of improving services to these children (Artz, 1999).

Teachers working in behaviour support noted that they highly valued the ability to work as members of a team from a solution focused, rather than a problem focused perspective. Also identified by these teachers as central to collaborative work and enhanced partnership across disciplines and professions were the following elements: having rapport with key people in agencies and developing credibility over time; close and open communication with parents; the presence of resource personnel and people who offer a variety of strategies or suggestions; and locating agencies directly in schools (Artz, 1999).

Parents of children in need of behaviour support reported feeling very appreciative of administrators, teachers, and youth and family counsellors who were able to listen to parents, to let them vent if necessary, and to take their concerns seriously. These parents also appreciated the team approach taken by those who worked with their children and believed that such teamwork enhanced their children's overall chances for positive growth and change (Artz, 1999). 


\section{Barriers to Caring and Collaboration}

Parents and workers noted these issues as barriers to effective work: an inability to listen; negative attitudes and a lack of negotiating skills in anyone involved; difficulties in communication with child welfare ministry workers and constant ministry flux; and haphazard inter-system communication. All parents who had been or were clients of the child welfare ministry mentioned difficulties with having to deal with constantly changing ministry workers. They noted that each time a worker changed, they must start the job of building a relationship again and must repeatedly recount their histories and must once more fight the same battles for needed resources.

Workers and parents felt that services would be more effective if: knowledge and expertise were better shared; all those who might be involved in service provision and the public were better educated regarding the developmental needs of children and especially children and youth with special needs; a cross-ministerial mechanism were in place for tracking clients and information sharing; and insuring the inclusion in decisionmaking of all interested and involved parties. Finally, parents suggested that, since boys in need of behaviour support far outnumbered girls, greater sensitivity to the gendered underpinnings of behaviour would assist all concerned with devising more effective intervention (Artz, 1999).

\section{Working With, not For or on Behalf of}

The success of all the work described here - violence prevention in schools that contributed to a 40 to $50 \%$ reduction in school-based violence (Artz, Riecken, Van Domselaar, \& Laliberté, 1994; Artz, 1998; Artz, Riecken, MacIntyre, Lam, \& Maczewski, 1997, 1998, 1999, 2000); the creation of a set of collaboratively developed recommendations for a community-based approach to dealing with violent under 12year-olds (Artz, 1999); the development of gender-sensitive professional development workshops by custody centre staff for custody centre staff (Artz, Blais, \& Nicholson, 2000b); and the design of a youth and worker friendly tool for needs assessment (Artz, Nicholson, Halsall, \& Larke, 2002) — was dependent upon an approach to research and development premised on equality of partnership, cooperation, and commitment to working with rather than for or on behalf of community agencies and institutions and those who were research participants.

The research and development projects described here were participatory in nature and are still being carried out, at least in part, by the participants, despite the projects having ended and funding having been cut. In the school district that participated in the studies on violence prevention and on developing a community-based approach to working with violent under 12-year-olds, teachers and agency workers remain committed to research and evaluation along with violence prevention and are continuing to develop and evaluate a variety of programs. In the custody centre, despite major adjustments in funding, changes in personnel, and moving from one building to another, staff remain involved in the design and delivery of staff development training. In the three 
communities that participated in the development of the gender-sensitive needs assessment tool, participants and their supervisors are disseminating the tool, and a ministry-based workshop is planned to assist workers in using the tool. It remains for others to conduct follow-up research on the legacy of these collaborative projects. Doing so will allow the replication not only of the successful programming that these partnerships developed, but also the replication of the processes that supported these successful partnerships. 


\section{References}

Anglin, J. (1999). Meaning and implications of the move to paramountcy of the safety and well-being of the child in child welfare legislation. Ottawa: Department of Justice, Canada.

Artz, S. (1998). Sex, power, and the violent school girl. Toronto: Trifolium.

Artz, S. (1999). A community based approach for dealing with chronically violent under twelve year old children. Ottawa: Department of Justice, Canada.

Artz, S., Blais, M., \& Nicholson, D. (2000a). Developing girls’ custody units. Unpublished Report, Justice Canada.

Artz, S., Blais, M., \& Nicholson, D. (2000b). Victoria Youth Custody Centre gendersensitive staff training curriculum. Unpublished Report, Justice Canada.

Artz, S., Nicholson, D., Larke, S., \& Halsall, E. (2002). Developing a gender-sensitive needs assessment tool for youth. Ottawa: National Crime Prevention Centre.

Artz, S., Riecken, T., Van Domselaar, T., \& Laliberté, P. (1994). A study of violence among adolescent female students in a suburban school district: Phase I: A survey of student life. Unpublished Report, British Columbia Ministry of Education, Victoria, BC.

Artz, S., Riecken, T., MacIntyre, B., Lam, E., \& Maczewski, M. (1997). A communitybased violence prevention project, University of Victoria and School District 62 at Sooke, BC. (Health Research Foundation fourth quarter report, December, 1996June 30, 1997). Vancouver, BC: British Columbia Health Research Foundation.

Artz, S., Riecken, T., MacIntyre, B., Lam, E., \& Maczewski, M. (1998). A communitybased violence prevention project, University of Victoria and School District 62 at Sooke, BC. (Health Research Foundation fifth quarter report, August 16, 1997 January 21, 1998). Vancouver, BC: British Columbia Health Research Foundation.

Artz, S., Riecken, T., MacIntyre, B., Lam, E., \& Maczewski, M. (1999). A communitybased violence prevention project. (BC Health Research Foundation, final report, September 1999). Vancouver, BC: British Columbia Health Research Foundation.

Artz, S., Riecken, T., MacIntyre, B., Lam, E., \& Maczewski, M. (2000). Theorizing gender differences in receptivity to violence prevention programs in schools. The B.C. Counsellor, 22(1), 7-35.

Berberet, H. (2006). Putting the pieces together for queer youth: A model of integrated assessment of need and program planning. Child Welfare, $L X X X V(2), 361-384$. 
Brendtro, L., Brokenleg, M., \& Van Bockern, S. (1990). Reclaiming youth at risk: Our hope for the future. Bloomington, IN: National Education Service.

British Columbia Ministry for Children and Families (2000). The youth policy framework. Victoria, BC: Author.

Canada, G. (1998). Reaching up for manhood: Transforming the lives of boys in America. Boston: Beacon Press.

Clarke, M. (2001). Influencing positive behavior change: Increasing the therapeutic approach of juvenile courts. Federal Probation, 65(1), 18-28.

Colton, M., Drury, C., \& Williams, M. (1995). Children in need: Definition, identification and support. British Journal of Social Work, 25(6), 711-728.

Daley, A. (1998). Lesbian invisibility in health care services: Heterosexual hegemony and strategies for change. Canadian Social Work Review, 15(1), 57-71.

DuBeau, T. (1998). Making a difference in the lives of gay and lesbian students. Reclaiming Children and Youth, 7(3), 164-168.

Garbarino, J. (1999). Lost boys: Why our sons turn violent and how we can save them. New York: Free Press.

Garmazy, N. (1971). Vulnerability research and the issue of primary prevention. American Journal of Orthopsychiatry, 41, 101-116.

Gilligan, C. (1982). In a different voice. Cambridge, MA: Harvard University Press.

Hannah-Moffat, K., \& Maurutto, P. (2003). Youth risk/need assessment: An overview of issues and practices. Ottawa: Department of Justice, Canada. On-line: www.justice.gc.ca.

Henderson, L., Aydlett, L., \& Bailey, D. (1994). Evaluating family needs surveys: Do standard measures of reliability and validity tell us what we want to know? Journal of Psychoeducational Assessment, 11(3), 208-219.

Hodges, K. (1999). Child and adolescent functional assessment scale (CAFAS). In. M. Maruish (Ed.), The use of psychological testing for treatment planning and outcomes assessment (2nd ed., pp. 321-664). Mahway, NJ: Lawrence Erlbaum.

Kemp, S. P., Whittaker, J. K., \& Tracy, E. M. (1997). Person-environment practice: The social ecology of interpersonal helping. New York: Aldine De Gruyter. 
Kroll, L., Woodham, A., Rothwell, J., Bailey, S., Tobias, C., Harrington, R., et al. (1999). Reliability of the Salford needs assessment schedule for adolescents. Psychological Medicine, 29(4), 891-902.

Leadbeater, B. J., Blatt, S. J., \& Quinlan, D. M. (1995). Gender-linked vulnerabilities to depressive symptoms, stress, and problem behaviours in adolescents. Journal of Adolescence, 5(1), 1-29.

Lezak, M. (1995). Neuropsychological assessment. Oxford, UK: Oxford University Press.

Maier, H. (1991). Developmental foundations of child and youth care work. In J. Beker \& Z. Eisikovits (Eds.), Knowledge utilization in residential child and youth care practice (pp. 25-48). Washington, DC: Child Welfare League of America.

Mangham, C., McGrath, P., Reid, G., \& Stewart, M. (1995). Resiliency: Relevance to health promotion discussion paper. Retrieved May 14, 2003 from http://www.hcsc.gc.ca/hppb/alcohol-otherdrugs/pube/resilney/discus.htm.

Masten, A. (1999). Commentary: The promise and perils of resilience research as a guide to preventive interventions. In M. Glantz \& J. Johnson (Eds.), Resilience and development: Positive life adaptations: Longitudinal research in the social and behavioral sciences (pp. 109-128). New York: Kluwer /Plenum Academic Press.

Miller, J. B. (1976). Toward a new psychology of women. Boston: Beacon Press.

Neisser, U., Boodoo, G., Bouchard, T. J., Boykin, A. W., Brody, N., Ceci, S. J., et al. (1996). Intelligence: Knowns and unknowns. American Psychologist, 51(2), 77101.

Nicholson, D., Artz, S., Armitage, A., \& Fagan, J. (2000). Working relationships and outcomes in multidisciplinary collaborative practice settings. Child and Youth Care Forum, 29(1), 39-73.

Ottenbacher, K., Taylor, E., Msall, M., \& Braun, S. (1996). The stability and equivalence reliability of the functional independence measure for children (WeeFIM). Developmental Medicine and Child Neurology, 38(10), 907-916.

Pipher, M. (1994). Reviving Ophelia: Saving the selves of adolescent girls. New York: Grosset/Putnam.

Plummer, D. (1999). One of the boys: Masculinity, homophobia, and modern manhood. New York: Harrington Park Press.

Pollack, W. (1998). Real boys: Rescuing our sons from the myths of boyhood. New York: Henry Holt. 
Reitsma-Street, M. (2004). Radical pragmatism: Prevention and intervention with girls in conflict with the law. In M. Hoskins \& S. Artz (Eds.), Working relationally with girls (pp. 119-137). Binghamton, NY: The Haworth Press.

Reitsma-Street, M., Artz, S., \& Nicholson, D. (2005). Canadian girls and crime in the twenty-first century. In J. Winterdyk (Ed.), Issues and perspectives on young offenders in Canada (3rd ed., pp. 57-82). Toronto: Nelson.

Richardson, B., (2001). Working with challenging youth: Lessons learned along the way. Philadelphia: Brunner-Routledge.

Ricks, F., \& Charlesworth, J. (2003). Emergent practice planning. New York: Kluwer Academic/Plenum Publishers.

Riecken, T. (2000). “What's your problem man?” (And how can I help?): Redesigning the landscape of boyhood. The B.C. Counsellor, 22(1), 37-43.

Sattler, J. M. (1992). Assessment of children: Revised and updated. (3rd ed.). New York: Jerome Sattler, Publisher Inc.

Sattler, J. M., \& Hoge, D. (2006). Assessment of children: Behavioral, social and clinical foundations (5th ed.). San Diego, CA: Jerome Sattler, Publisher, Inc.

Sharpe, J. (2001a). Presentation of the education of young people at the August, 2001 Civicus World Assembly Conference, Vancouver, BC.

Sharpe, J. (2001b). Presentation of national youth policies: A working document from the point of view of "non-formal education" youth organizations at the August, 2001 Civicus World Assembly Conference, Vancouver, BC.

Tanenbaum, L. (1999). Slut! Growing up female with a bad reputation. New York: Seven Stories Press.

Taylor, J. M., Gilligan, C., \& Sullivan, A. M. (1995). Between voice and silence. Cambridge, MA: Harvard University Press.

Towberman, D. (1992). National survey of juvenile needs assessment. Crime and Delinquency, 38(2), 230-238.

Van Bockern, S., \& Brendtro, L. K. (1999). The developmental audit of delinquency. Proposal submitted to the W. K. Kellogg Foundation by Augustina College and the Reclaiming Youth Institute.

Van Bockern, S. (1998). Meeting the needs of our youth. Reclaiming Children and Youth, 7, 172-175.

Werner, E. E., and Smith, R. S. (1992). Overcoming the odds: High risk children from birth to adulthood. Ithaca, NY: Cornell University Press. 